\title{
Satellite weather around the corner?
}

\section{A cool appraisal of the contribution of Earth satellites to weather forecasting reveals basic and practical problems to be solved. Measuring water vapour may be the next objective.}

Meteorologists, or at least those who work as weather forecasters, have something of the social status of economists. People look to them for good news and blame them when it is otherwise. So much has been clear, in the past few weeks, on both sides of the North Atlantic. On the eastern seaboard of the United States, the televison weathermen forecast the Great New Year storm with all the zeal of physicians bent on avoiding a malpractice suit, and then complained when the snowfall was merely normal for the time of year. In Britain, where belief in the effectiveness of snowploughs has yet to take hold, meteorologists have been given no thanks for having forecast a spell of cold weather that should be considered normal so near to the Arctic Circle.

Will not all this change when sufficiently elaborate atmospheric circulation models have been bedded down in suitably large computers, and when the data that they use are collected by Earth satellites capable of measuring to whatever resolution may be required? Not so, it seems, to judge from a thoughtful review of the usefulness of satellite data in numerical weather prediction by R.D. Isaacs, R.N. Hoffman and L.D. Kaplan of Atmospheric and Environmental Research Inc. (Rev. Geophys. 24, 701-43; 1986).

Numerical weather forecasting has improved immensely in the quarter of a century since the US satellite TIROS I was launched, but the contribution of satellites has been less important than the improvement of forecasting technique. The good news is that satellites have yet to yield much of what they have always promised.

On one thing, however, there is general agreement: before TIROS I, when the data for the Southern Hemisphere were derived largely from the adventitious routes taken by ocean-going ships, prediction south of the Equator was much more hazardous than now. Imperfect though satellite data may still be, they have filled gaps that would never otherwise have been bridged.

Elsewhere, the forecasters' skill has improved dramatically if selectively. Isaacs and his colleagues demonstrate a dramatic improvement since the 1950 s of the accuracy with which the National Meteorological Center (Washington, DC) can forecast the height of the $500-\mathrm{m}$ bar level above North America a day and a half in advance; the success rate has gone from a third to three-quarters in 30 years as the circulation models have improved. But the numerical weather forecasters are hardly any better now than then at forecasting precipitation a day ahead.

There are several difficulties, all of them persuasive that the promise of satellites is still as bright as in the $1950 \mathrm{~s}$. The most obvious is the problem that runs through the whole of geophysics - that of inferring from a set of measurements of a few quantities at a fixed point the distribution of some other quantity with yet another. Exploration geologists are forever trying to tell the structure of a sedimentary basin (and geophysicists the structure of the Earth) from measurements of the seismic signals generated by one event at a few places where there happen to be instruments.

The same inversion problem confronts those who would use measurements from a satellite of the radiation from the Earth's atmosphere as a function (but crudely) of the frequency to infer the distribution of atmospheric temperature as a function of altitude: one needs not merely measurements accurate enough to survive the computational barbarism of the computers, but also a theory of how one set of variables is related to the other. Often, of course, the measurements are made only because there is no theory in sight. Isaacs and his colleagues make the sensible point that, meanwhile, it would make sense to choose ranges for satellite measurements calculated to bear most sensitively, within the framework of what is known about the behaviour of the atmosphere, on the parameters likely to be most useful.

For the time being, the most useful measurements of the atmosphere appear to be temperature measurements. Thanks to infrared intruments based on interferometric principles (developed at the University of Chicago by W.L. Smith and his colleagues and installed on satellites such as Nimbus $N$ ), the temperature profile beneath the line of sight of a satellite can be determined with a vertical resolution of 5 or $6 \mathrm{~km}$ even in the troposphere. Isaacs and his colleagues make the disturbing observation that measurements of temperature in the troposphere from satellites and by radiosondes nevertheless appear to differ from each other by a few degrees. By contrast, the horizontal resolution provided from satellites is better than anything the meteorologists could imagine when all data came from radiosondes launched from fixed points on the Earth's surface, usually twice a day.

The real trouble with satellites is that, apart from temperature, they have little to say that bears on the meteorology of weather forecasting. Vertical profiles of water vapour concentration are obviously important, if only because they are at once a driving force of the thermodynamics of the atmosphere and a symptom of its condition. The snag is that there is as yet no proven system for telling what the atmospheric profile of water vapour concentration may be. That stands out as the next important problem for the weather satellite designers.

Meanwhile, Isaacs and his colleagues have an interesting problem to tackle, whose method may be instructive in other fields. Relying on the availability of substantial computer power to replicate the results of atmospheric modelling using different data sets as starting material, they have set out to compare the outcome of numerical weather forecasts with and without the data provided by weather satellites. Vividly, they use the term "impact test" to describe what they have done. Possibly, one of these days, economists will find themselves compelled to run their economic models with and without the benefit of the wisdom they presume themselves to have added. What the meteorologists conclude is that data on the wind speed in the atmosphere, sometimes available from (ground-based) lidar measurements based on the reflection of laser pulses from airborne dust, appear to be powerful determinants of the numerical models. There is no obvious means by which data of that kind might be collected from observations from a satellite in orbit around the Earth. Maybe, some will say, there is a quite different parameter that will serve this purpose, which is another way of saying there is more physics to be done.

None of this implies that weather forecasting by numbers will soon be as precise as the calculation of the calendar, or that satellite observations have nothing to contribute to such a process. What is needed, rather, are some new ideas for the measurement of water vapour as a function of height, which will almost certainly require a new generation of experimental meteorological satellites even more massive than those now in service. If that would excuse the weathermen from their habitual excesses, the cost might be justified by the benefit. John Maddox 